\title{
SOLUÇÕES E ESTRATÉGIAS DE ALUNOS EM ATIVIDADES DIDÁTICAS SOBRE ISOMETRIAS ENVOLVENDO O BORDADO EM PONTO CRUZ
}

\section{SOLUTIONS AND STRATEGIES IN TEACHING STUDENTS ABOUT ISOMETRIES ACTIVITIES INVOLVING EMBROIDERY ON CROSS STITCH}

\author{
Sabrine Costa Oliveira, Sandra Aparecida Fraga da Silva \\ Instituto Federal do Espírito Santo \\ E-mail: binecosta@gmail.com, sandrafraga7@gmail.com
}

\section{Resumo}

Este trabalho tem por objetivo investigar soluções e estratégias de alunos em atividades sobre isometrias envolvendo o bordado em ponto cruz. Em 2013, aplicamos atividades em duas turmas de 8 ㅇ ano de uma escola estadual de ensino fundamental em Vitória/ES, parceira do Pibid. Examinamos as estratégias de soluções dos alunos e classificamos em classe $A$, classe $B$ e classe $C$. As análises das soluções indicaram que, embora os alunos não tivessem estudado os conceitos sobre transformações geométricas anteriormente, eles se apropriaram de conceitos trabalhados de forma intuitiva e as atividades realizadas proporcionaram um aprendizado dinâmico e criativo nas aulas de geometria com a utilização dos bordados em ponto cruz. Os erros cometidos pelos alunos serviram para analisar e refletir sobre dificuldades de aprendizagem do conteúdo de isometrias.

Palavras-chave: transformações geométricas. ponto cruz. ensino de geometria. ensino de matemática.

\begin{abstract}
This paper presents an outline of the analysis carried out on a course conclusion work, which aimed to investigate which solutions and strategies are produced by students in educational activities on isometries involving embroidery in cross stitch. The activities were implemented in eight classes with two groups of 8 years, a total of 28 students from a state school in Vitória / ES, partner of PIBID, developed during the year 2013. The solutions of the activities were examined in order to identify the strategies used to address them and then were sorted by categories developed by the author. The analysis of the solutions indicated that while students had not studied the concepts of geometric transformations earlier, they appropriated worked concepts intuitively and activities provided a dynamic and creative learning in geometry lessons with the use of embroidery in point cross. The mistakes made by students served to analyze and reflect on learning difficulties isometries content.
\end{abstract}

Palavras-chave: geometric transformations. cross stitch. geometry teaching. math education. 


\section{INTRODUÇÃO}

Estudos de diversos pesquisadores da área de educação matemática evidenciam a ausência do ensino de geometria nas escolas (PAVANELLO, 1993; LORENZATO, 1995; FRAGA, 2004), esse fato reflete no conhecimento dos professores em atuação. Os professores não se sentem seguros para ensinar a geometria, devido ao pouco ou nenhum contato que tiveram com esse conteúdo, tanto na educação básica quanto na graduação, e por esse motivo a excluem de suas aulas com a justificativa que esse conteúdo é maçante e irrelevante ao ensino básico (DANA, 1994; MABUCHI, 2000).

Por outro lado, os documentos oficiais, como os Parâmetros Curriculares Nacionais e o Plano Nacional do Livro Didático recomendam que o ensino da geometria seja articulado com a arte. O estudo das isometrias por meio dos bordados em ponto cruz é uma maneira de integrar o ensino da geometria às artes. Segundo os Parâmetros Curriculares Nacionais (BRASIL, 1998), o ensino das artes proporciona aos alunos o desenvolvimento da visualização espacial, da análise e do raciocínio geométrico, e ele estará habilitado a construir textos e desenvolver estratégias pessoais para solucionar um problema matemático. Nessa direção, a arte contribui na expansão do universo cultural dos indivíduos, abrindo espaço a participação social, mobilizando sentidos e capacidades essenciais para o desenvolvimento humano: a imaginação e a observação. $E$, o estabelecimento de ligações entre a matemática e arte auxilia na compreensão dos conceitos e procedimentos geométricos (OLIVEIRA, 2014).

A análise das reflexões, translações, rotações são fontes ricas para o desenvolvimento dos conceitos geométricos em sala de aula. Investigando a matemática que está presente nos diversos campos da atividade humana, observamos que atividades envolvendo transformações geométricas contribuem na estrutura do pensamento e no progresso do raciocínio dedutivo, destacamos em especial os bordados em ponto cruz. De acordo com as recomendações dos PCN's para o 3ㅇ e 4 ciclo:

As atividades que envolvem as transformações de uma figura no plano devem ser privilegiadas nesses ciclos, porque permitem o desenvolvimento 
de conceitos geométricos de uma forma significativa, além de obter um caráter mais "dinâmico" para este estudo (BRASIL, 1998, p. 124).

Além disso, as atividades de transformações geométricas são fundamentais para desenvolver habilidades de percepção espacial e podem favorecer a construção das noções de congruência e semelhança de figuras planas. E ainda, as atividades de geometria se apresentam com potencialidades e possibilidades de tornar-se uma tarefa exploratórioinvestigativa. Grando et al. (2008) define que tarefas exploratório-investigativas são atividades abertas que permitem diferentes perguntas, estratégias de resolução e processos de validação.

O uso de gráficos em ponto cruz é um recurso didático que auxilia na visualização das propriedades, facilitando a construção dos conceitos sobre transformações geométricas. Pais (2000) afirma que a finalidade da utilização de materiais ou recursos didáticos por parte dos professores de ensino fundamental é amenizar dificuldades de ensino existentes em determinados conteúdos matemáticos. A seguir apresentamos alguns gráficos utilizados nas atividades como exemplos.

Figuras 1 e 2. Gráficos de reflexão da cereja e das flores.
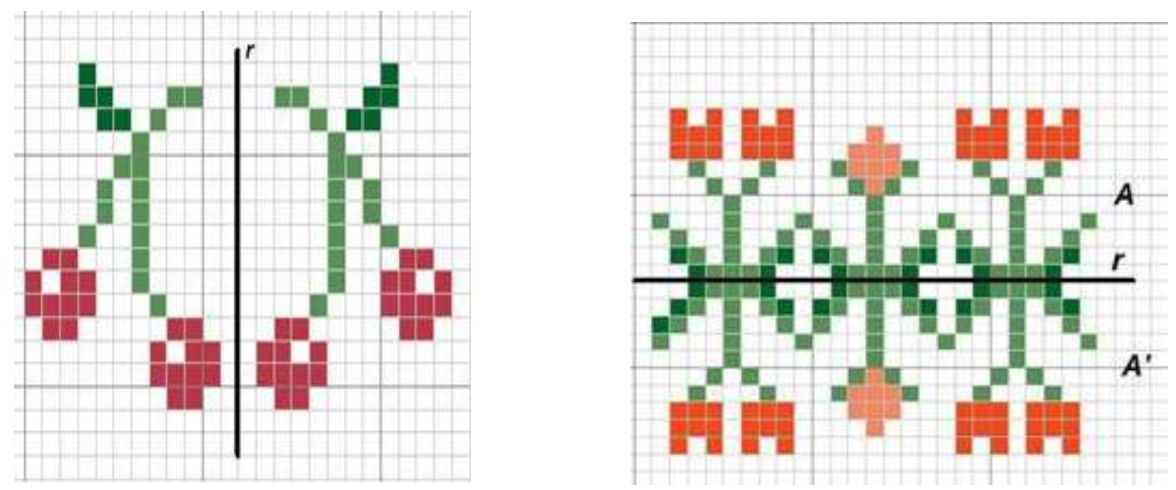

Fonte: dados da pesquisa.

Os processos de ensino e aprendizagem da matemática, por muitos anos e ainda hoje, estão ligados à repetição de exercícios e memorização de fórmulas, o que para os alunos está associado a sofrimentos e fracassos escolares (FAINGUELERNT; NUNES, 2006). E, segundo os 
Parâmetros Curriculares Nacionais:

Em nosso país o ensino de Matemática ainda é marcado pelos altos índices de retenção, pela formalização precoce de conceitos, pela excessiva preocupação com o treino de habilidades e mecanização de processos sem compreensão (BRASIL, 1998, p.19).

Ao trazermos a arte para a sala de aula de matemática é possível transformar o ambiente escolar em um espaço de criação, prazer, construção de conhecimentos e de descobertas.

Este trabalho é fruto de análises realizadas em um trabalho de conclusão de curso, que objetivou analisar a soluções de atividades didáticas sobre isometrias produzidas por alunos do 8o ano de uma escola estadual em Vitória/ES, parceira do PIBID, no ano de 2013.

\section{PROCEDIMENTOS METODOLÓGICOS}

O presente trabalho é uma pesquisa de caráter qualitativa e exploratória, sustentada por observação direta da situação de aprendizagem, que visa analisar soluções de atividades didáticas sobre transformações geométricas com aplicações em bordados de ponto cruz. Segundo Gil (2008), a pesquisa exploratória consiste em desenvolver, esclarecer e modificar conceitos e ideias, com vistas à formulação de problemas mais precisos ou hipóteses pesquisáveis para estudos posteriores. Seu objetivo é proporcionar uma visão geral sobre um determinado fenômeno.

As atividades de isometrias utilizadas nessa pesquisa foram elaboradas durante duas pesquisas de iniciação científica, desenvolvidas no Programa Institucional de Voluntários de Iniciação Científica - PIVIC do Instituto Federal do Espírito Santo, realizadas no período de julho de 2011 a agosto de 2013. Para a aplicação das atividades foram ministradas oito aulas com duração de 55 minutos cada. No quadro a seguir, apresenta o resumo de todas as aulas ministradas nessa pesquisa com a descrição sucinta das atividades realizadas: 
Quadro 1. Resumo das atividades.

\begin{tabular}{|c|l|}
\hline Aulas & \multicolumn{1}{|c|}{ Atividades desenvolvidas } \\
\hline $22 / 05 / 13$ (2 aulas) & $\begin{array}{l}\text { Questionário diagnóstico; } \\
\text { Aula expositiva sobre simetria e reflexão; atividades. }\end{array}$ \\
\hline $05 / 06 / 13$ (2 aulas) & $\begin{array}{l}\text { Término das atividades de reflexão; } \\
\text { Aula expositiva sobre translação e rotação; } \\
\text { Atividades de translação e rotação. }\end{array}$ \\
\hline $12 / 06 / 13$ (2 aulas) & $\begin{array}{l}\text { Construção de desenho livre em malha quadriculada que contenha a isometria, } \\
\text { escolhida por meio de sorteio; } \\
\text { Atividades de simetria e reflexão nos gráficos em ponto cruz. }\end{array}$ \\
\hline $26 / 06 / 13$ (2 aulas) & $\begin{array}{l}\text { Atividades de rotação e translação nos gráficos em ponto cruz; } \\
\text { Confecção de barras em ponto cruz pelos alunos. }\end{array}$ \\
\hline $02 / 07 / 13$ (2 aulas) & Questionário final. \\
\hline
\end{tabular}

Fonte: dados da pesquisa.

Com a intenção de investigar quais resoluções são realizadas pelos alunos em atividades envolvendo as transformações geométricas e o ponto cruz, analisamos as soluções das atividades aplicadas no desenvolvimento da iniciação científica. Nossa intenção foi identificar erros cometidos pelos alunos de ensino fundamental, obtendo informações que nos permitam avançar no conhecimento de possíveis causas desses erros. As estratégias empregadas na resolução das atividades foram analisadas com o objetivo de verificar a compreensão tanto do conteúdo quanto do enunciado pelos participantes, além de evidenciar as diferentes resoluções das atividades. Cury (2007) afirma que a análise das respostas de alunos pode ser utilizada pelo professor tanto como metodologia de ensino quanto como metodologia de pesquisa sobre a prática docente da sala aula. Enquanto, metodologia de pesquisa procura-se entender como o aluno produziu a resposta contribuindo para a formação de novos olhares sobre as respostas dos alunos. E, como metodologia de ensino o professor deve investigar a causa do erro e os utiliza para retomar os conteúdos os quais os alunos apresentam dificuldades.

Segundo Bardin $(2009$, p.41) a análise de erros de uma produção escrita, pode ser feita a partir de documentos como respostas a questionários, testes ou experiências. A autora apresenta três etapas para a análise de conteúdo: pré-análise, a exploração do material e o tratamento dos resultados. Ao unir as etapas de Bardin (2009) com os procedimentos de 
Cury (2007) para a análise das respostas de estudantes, percorrermos o percurso apresentado no quadro abaixo:

Quadro 2. Resumo das etapas de análise.

\begin{tabular}{|c|l|}
\hline Etapas da Análise & \multicolumn{1}{|c|}{ Etapas da Pesquisa } \\
\hline Pré-análise & $\begin{array}{l}\text { 1. Leitura do material para identificação de erros } \\
\text { e estratégias utilizadas nas soluções de atividades } \\
\text { resolvidas pelos alunos de 8o ano. }\end{array}$ \\
\hline Exploração do material & $\begin{array}{l}\text { 2. Releitura cuidadosa do material para } \\
\text { selecionar o corpus da pesquisa e elaboração } \\
\text { das categorias de análise. }\end{array}$ \\
\hline Tratamento dos resultados & $\begin{array}{l}\text { 3. Análise do corpus da pesquisa, segundo as } \\
\text { categorias, e apresentação das categorias por } \\
\text { meio de exemplos dos erros cometidos. }\end{array}$ \\
\hline
\end{tabular}

Fonte: dados da pesquisa.

\section{RESULTADOS E DISCUSSÃO}

As atividades de isometrias e ponto cruz foram elaboradas com o auxilio do programa PCStitch, que é um software gratuito que permite criar gráficos em ponto cruz e nos auxiliou na produção de atividades. Os alunos das turmas acompanhadas apresentavam um índice grande de faltas, por isso foi necessário realizar uma seleção das atividades resolvidas pela maioria dos alunos, em especial as que possuem relação com os gráficos de bordado em ponto cruz.

Diante da seleção e da análise prévia do corpus da pesquisa e após a listagem de todas as resoluções, estas foram analisadas e categorizadas, obtendo três classes, descritas e exemplificadas a seguir:

Classe A - Correspondem às soluções corretas. Neste caso foram encontradas várias estratégias de resolução das atividades.

1 Segundo Bardin (2009, p.122) o corpus da pesquisa é o conjunto dos documentos que será submetido aos procedimentos de análises. 
Classe B - Correspondem às soluções parcialmente corretas. Nessa categoria, apesar da solução certa, não há como afirmar se o aluno acertou porque compreendeu o conteúdo ou por acaso.

Classe $C$ - Correspondem às soluções incorretas. Foram identificados erros como: interpretação de enunciados, dificuldade no conteúdo e falta de atenção (confusão das transformações).

Em seguida, apresentamos um recorte que ilustra cada categoria por meio de exemplos retirados do corpus da pesquisa e as soluções e estratégias utilizadas pelos alunos são analisadas em detalhes.

A questão a seguir envolve o conceito de reflexão e tem o seguinte enunciado:

Quadro 3. Atividade de reflexão horizontal da maçã e borboleta.

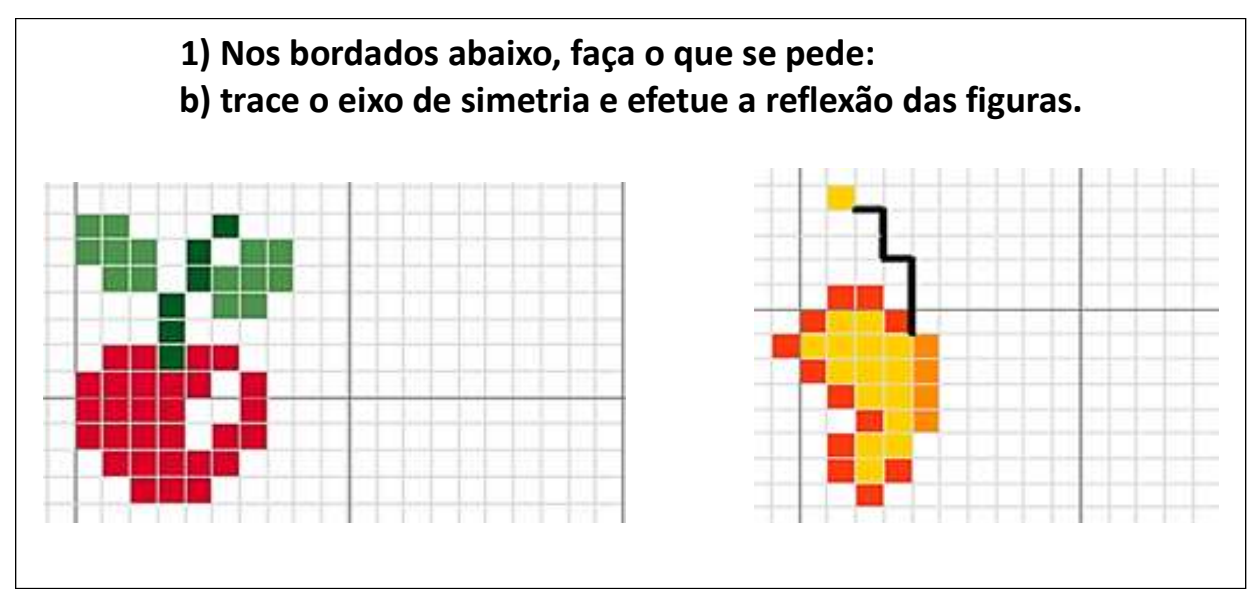

Fonte: acervo da autora, 2013.

A atividade de reflexão da maçã apresentava um nível maior de complexidade, devido ao detalhe nas folhas, sete alunos acertaram (classe A) essa atividade apresentando a resolução a seguir. 
Figuras 3 e 4. Soluções de atividades do alunos 2 (8ㅇ ano A) e 6 (8ㅇano B) respectivamente.
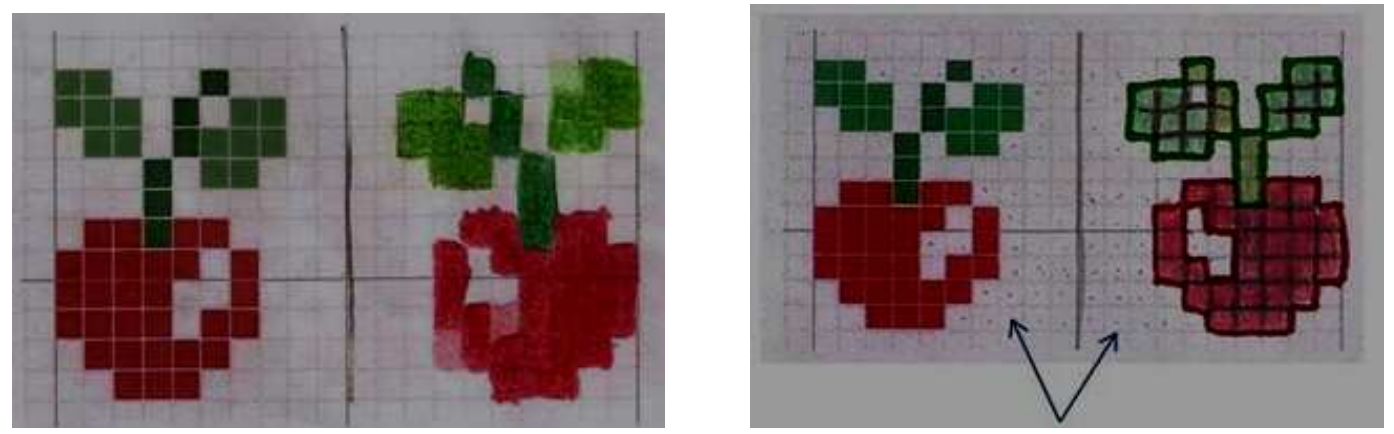

Fonte: acervo da autora, 2013.

Note que na reflexão da maçã, os alunos utilizaram a marcação da malha quadriculada (linha mais escura) como eixo de simetria. Percebemos na resolução do aluno na figura 4 o uso de estratégia de marcação na contagem da distância em que deveria manter até os quadradinhos que deveriam ser pintados, como pode ser observado destacado na imagem, e depois ainda contornou com canetinha colorida à figura. Já o aluno da figura 3 tinha realizado errada a reflexão, porém apagou e corrigiu, terminando a atividade corretamente. Já a atividade de reflexão da metade da borboleta foi acertada por cinco alunos, e alguns traçaram o eixo de simetria no meio da figura (fig. 5) e outros ao lado da figura (fig. 6). Como o enunciado solicitava que os estudantes traçassem o eixo de simetria e efetuasse a reflexão, e ambos fizeram isso, apesar de diferente, as duas soluções foram consideradas corretas.

Figuras 5 e 6 . Soluções de atividade dos alunos 2 ( $8^{\circ}$ ano A) e 6 ( $8^{\circ}$ ano B), respectivamente.
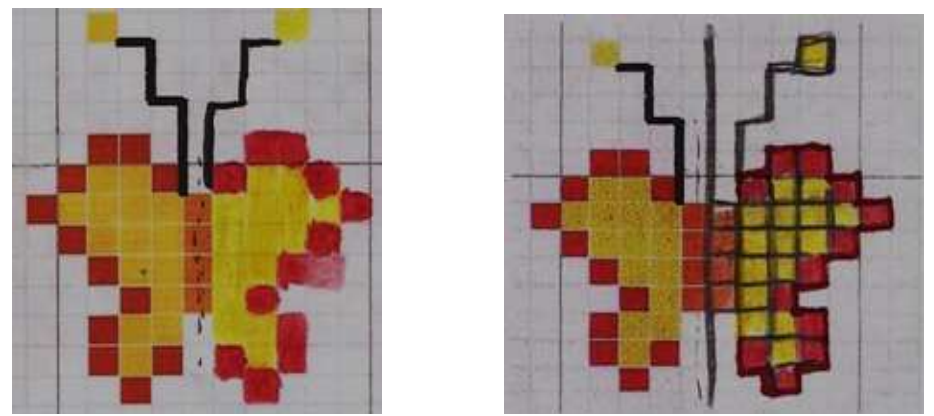

Fonte: acervo da autora, 2013. 
As soluções diferentes para um mesmo problema envolvendo atividades sobre geometria justificam-se pelo fato de que essas atividades se apresentam com potencialidades e possibilidades de tornar-se uma tarefa exploratório-investigativa. Segundo Grando et al. (2008) as tarefas exploratório-investigativas são problemas abertos que possibilitam diferentes perguntas, estratégias de resolução e processos de validação. Nesse sentido, entendemos que cada aluno produz uma solução de acordo com a interpretação de sua realidade, utilizando os conhecimentos que possui e decidindo a maneira como utilizá-los para solucionar a atividade.

Ainda na classe $A$, destacamos a reflexão do cacho de uva.

Quadro 4. Atividade de reflexão horizontal do cacho de uva.

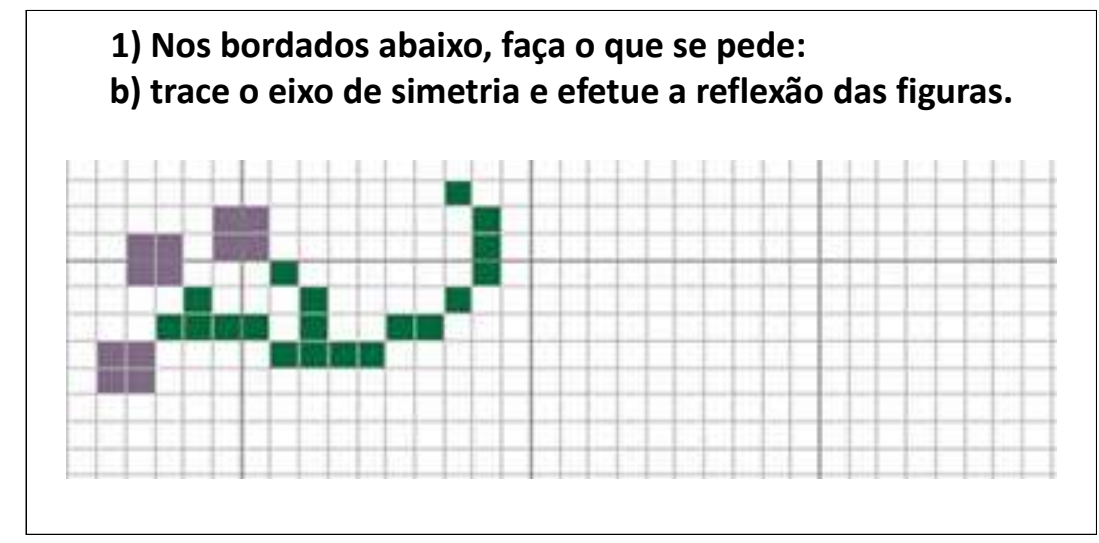

Fonte: acervo da autora, 2013.

Os dez alunos que acertaram a questão e foram incluídos na classe $A$, apresentaram as seguintes soluções: 
Figura 7. Solução de atividade aluno 7 (8o ano A).

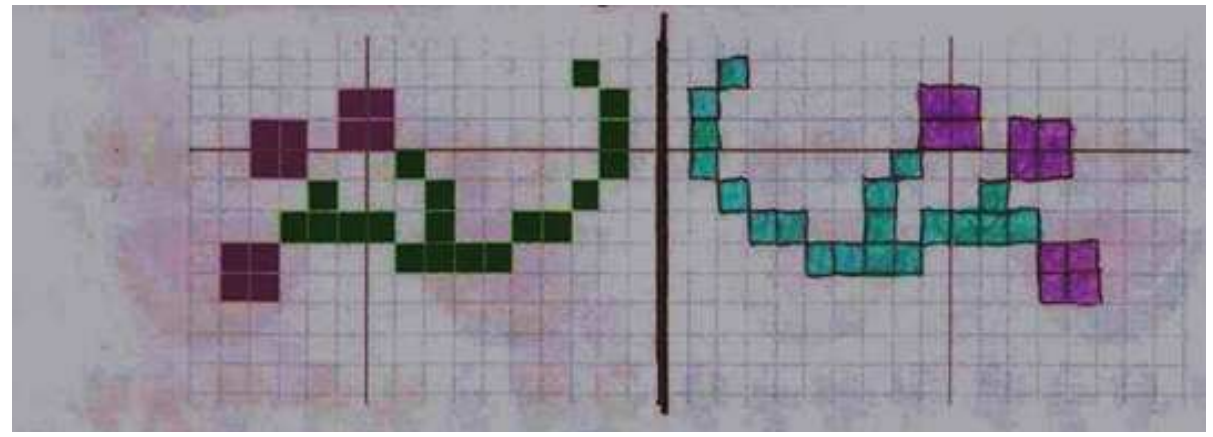

Fonte: acervo da autora, 2013.

Figura 8. Solução de atividade aluno 2 ( 8 ㅇ ano B).

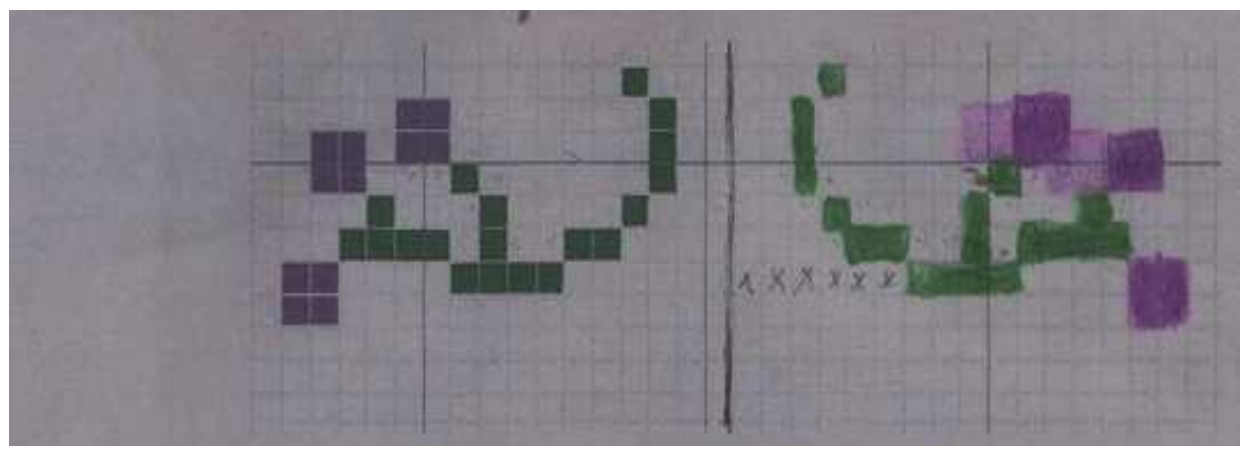

Fonte: acervo da autora, 2013.

A maioria dos alunos utilizou a marcação da linha mais escura contida na malha quadriculada como eixo de simetria. Note que o segundo aluno não utiliza essa estratégia, mas traça o eixo de simetria ao lado da linha mais escura. Também é importante observar que na figura 7, o aluno fez primeiro o contorno da figura a ser refletida e depois coloriu. Já na figura 8, o aluno fez sem o contorno, porém, escolheu um ponto e realizou com marcações de " $x$ " a distância inicial que deveria iniciar a pintura.

Para resolver essa questão alguns alunos utilizaram como recurso o espelho e até o visor do celular, a fim de visualizar a reflexão. Veja a seguir. 
Figuras 9 e 10. Alunas utilizando espelho e visor do celular como recursos.
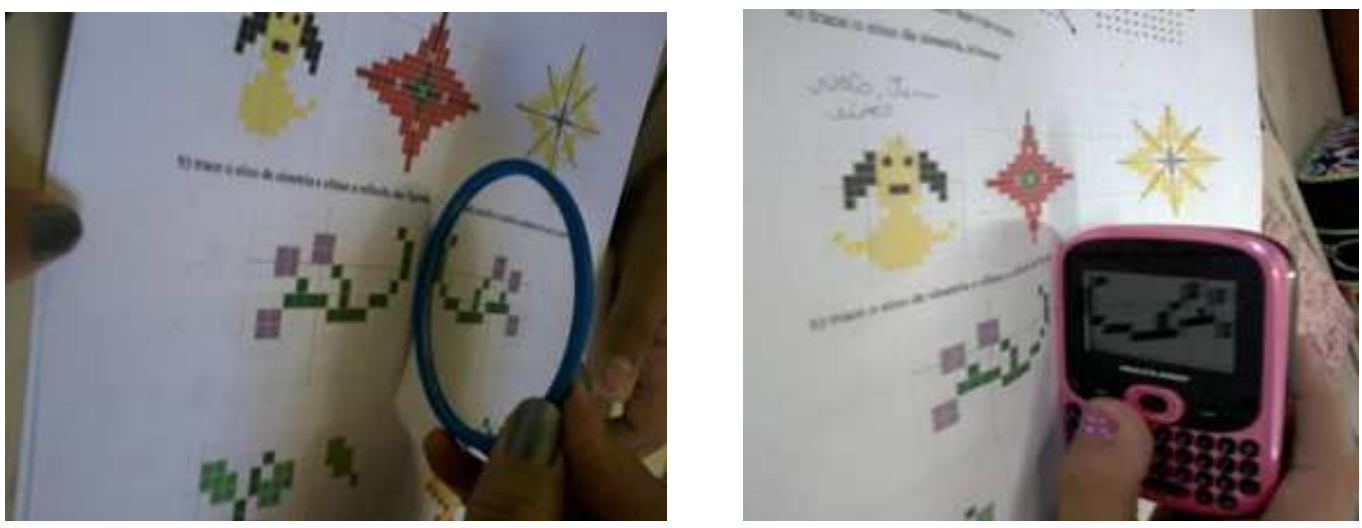

Fonte: acervo da autora, 2013.

Segundo Pais (2000) o uso de recursos didáticos em sala de aula tem como finalidade dar suporte no processo de ensino e de aprendizagem, facilitando o processo de aquisição do conhecimento. Porém, concordamos com Veloso et al. (2009) que todos os materiais possuem potencialidades e limitações, cabendo ao professor estar atento a essas especificidades.

As atividades de rotação inseridas na classe $A$, possuem o enunciado abaixo:

Quadro 5. Atividade de rotação.

1) Nos bordados abaixo, faça o que se pede:

a)

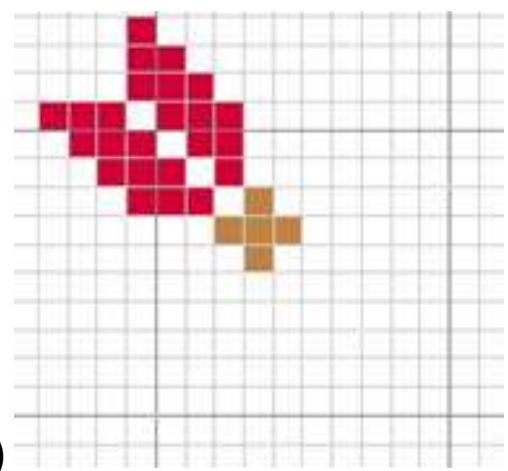

Fonte: acervo da autora, 2013 
As soluções apresentadas nas figuras 7 e 8 representam as soluções realizadas por quatorze alunos na atividade de rotação ao item (a) considerado correto foram:

Figuras 7 e 8. Soluções de atividades dos alunos 5 ( $8^{\circ}$ ano A) e 3 ( $8^{\circ}$ ano A), respectivamente.
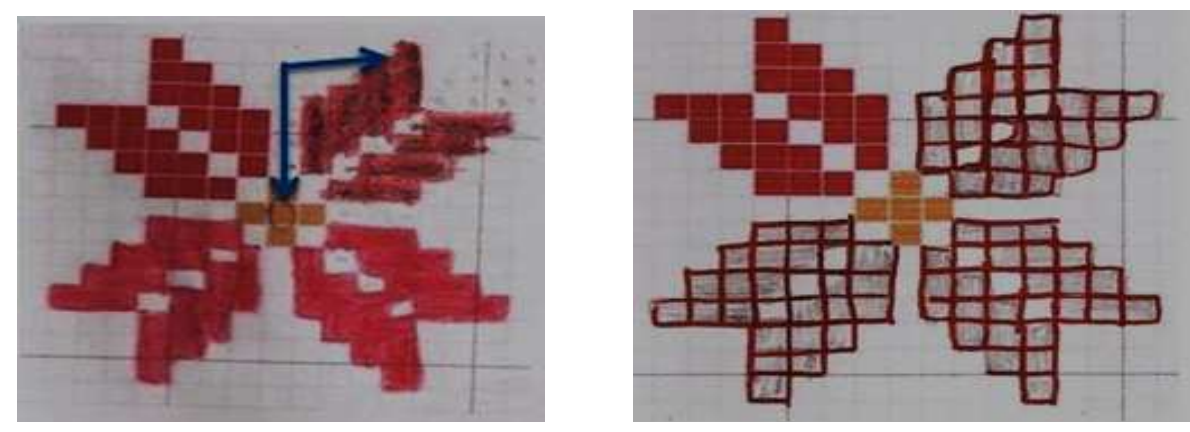

Fonte: acervo da autora.

Note que o enunciado dessa questão não determina o centro e o sentido em que a rotação deve ser realizada, explica somente que a rotação da pétala deve ser feita para formar uma flor. Nessa questão podemos destacar as diferentes estratégias utilizadas, a figura 7 mostra que o aluno iniciou fazendo a pintura de pontinhos para orientar a translação e depois concluiu fazendo a pintura na malha quadriculada. Já na figura 8 , percebemos que o aluno fez a pintura com lápis de escrever e depois fez o contorno em vermelho, optando por não colorir.

Figura 9. Resolução da atividade de translação aluno 4 (8o ano A).

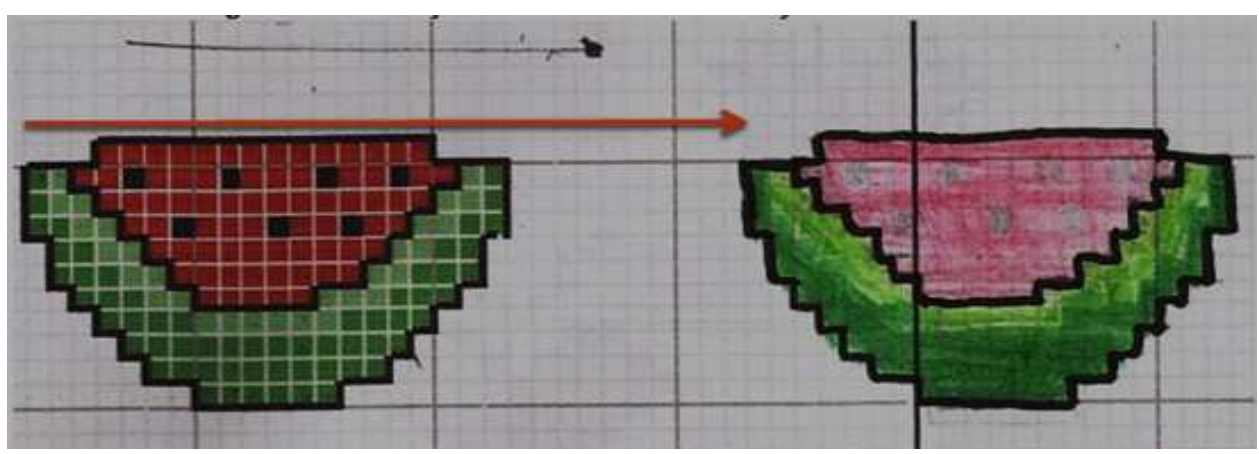

Fonte: acervo da autora, 2013.

Repare na figura 9, incluída na classe B que apesar do aluno ter utilizado um vetor para 
orientar a translação, ele não se atentou à definição. A translação é definida por um segmento orientado que possui o mesmo comprimento e mesmo sentido, no entanto o aluno acertou o sentido e errou o comprimento do vetor. Ainda assim, essa solução foi considerada parcialmente correta, pois percebemos que o aluno possui a ideia correta segundo a definição, porém apresentou uma falta de atenção. Além disso, observamos que ele foi o único aluno a utilizar essa ideia, ainda nessa questão é importante notar que o aluno fez o contorno preto evidenciado no gráfico de ponto cruz. As análises realizadas para classe B não são conclusivas, são apenas hipóteses sobre os erros dos alunos. Para ter conclusões precisas seria necessária uma entrevista com os alunos participantes da pesquisa após a aplicação das atividades.

$\mathrm{Na}$ atividade de reflexão da maçã treze respostas foram incluídas na classe C. Os erros cometidos possuem relação com a falta de atenção dos alunos, pois eles confundiram a transformação geométrica a ser executada nas atividades.

Figuras 10 e 11. Soluções de atividades dos alunos 7 ( $8^{\circ}$ ano B) e 1 ( $8^{\circ}$ ano A), respectivamente.
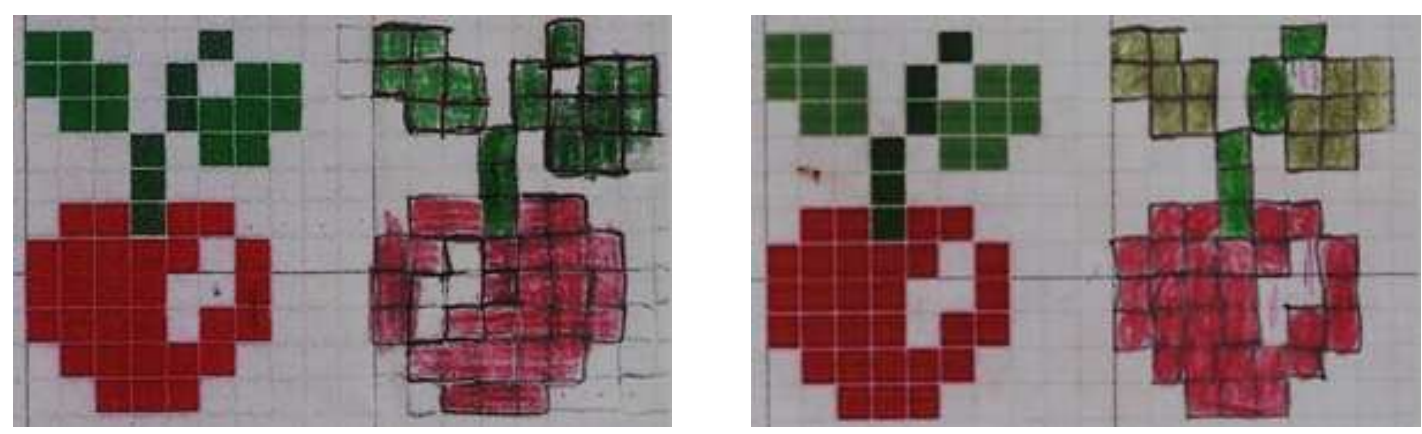

Fonte: acervo da autora, 2013.

Acreditamos baseados em Pais (2000) que a causa desse erro é o que o autor denomina de configuração geométrica. Segundo ele, em relação às noções geométricas mais elementares, verificamos a predominância de algumas figuras particulares encontradas com frequência nos livros, cadernos e em outros suportes do saber escolar. Trata-se de um desenho encontrado com relativa frequência no contexto do ensino e da aprendizagem escolar, ou seja, entendemos que é comum encontrarmos desenhos nos quais uma figura é transladada 
do que refletida. A análise dos erros da classe $C$ permitiu concluir que os alunos apresentaram falta de atenção com relação aos enunciados e por esse motivo confundiram as transformações geométricas.

\section{CONSIDERAÇÕES FINAIS}

Apresentamos neste texto, um recorte das análises realizadas numa pesquisa de conclusão de curso, que teve por objetivo investigar quais resoluções são realizadas pelos alunos em atividades envolvendo as transformações geométricas e o ponto cruz e analisar as estratégias empregadas nas resoluções. Em síntese, verificamos que os alunos foram capazes de construir o próprio conhecimento por meio de atividades didáticas sobre isometrias envolvendo o bordado em ponto cruz e orientados pela pesquisadora. $E$, além disso, também verificamos uma mudança no ambiente escolar, pois a aula se tornou dinâmica e produtiva com as resoluções das atividades. Salientamos que nossa pesquisa refere-se a duas turmas com vinte e oito alunos, logo não podemos considerar os resultados obtidos com esses alunos como ideal. Porém, consideramos que estes alunos avançaram em seus conhecimentos de forma intuitiva sobre transformações geométricas, embora não tivessem estudado esse tem.

\section{REFERÊNCIAS}

BARDIN, Laurence. Análise de Conteúdo. 4a ed. Lisboa: Edições 70, 2009.

BRASIL, Secretaria de Educação Fundamental. Parâmetros Curriculares Nacionais: Matemática - 5a a 8a séries. Brasília: MEC/SEF, 1998.

CURY, Helena Noronha. Análise de erros: o que podemos aprender com as respostas dos alunos. Belo Horizonte: Autêntica, 2007.

DANA, Marcia. E. Geometria - um enriquecimento para a escola elementar. In: LINDQUIST, Mary Montgomery; SHULTE, Albert P. Aprendendo e Ensinando geometria. São Paulo: Atual, 1994. 
FAINGUELERNT, Estela Kaufman; NUNES, Kátia Regina Ashton. Fazendo arte com a matemática. Porto Alegre: Artmed, 2006.

FRAGA, Sandra Aparecida. Um estudo sobre triângulos em livros didáticos a partir do movimento da matemática moderna. 2004. Dissertação (Mestrado em Educação) Programa de Pós-Graduação em Educação, Universidade Federal do Espírito Santo, Vitória.

GIL, Antônio Carlos. Métodos e Técnicas de Pesquisa Social. 6ạ Ed. São Paulo: Atlas, 2009.

GRANDO, Regina Célia; NACARATO, Adair Mendes; GONÇALVES, Luci Mara Gotardo. Compartilhando saberes em geometria: investigando e aprendendo com nossos alunos. Caderno Cedes: Campinas, vol. 28, no 74, p. 39-56, jan./abr. 2008. Disponível em <http://www.scielo.br/pdf/ccedes/v28n74/v28n74a04.pdf> Acesso em 20/03/2014.

LORENZATO, Sergio. Por que não ensinar geometria? A educação matemática em revista, Blumenau: SBEM, n. 4, 1ㅇ semestre, p. 3-13, 1995.

MABUCHI, Setsuko Takara. Transformações Geométricas: a trajetória de um conteúdo ainda não incorporado às práticas escolares nem à formação de professores. 2000. Dissertação (mestrado) - Programa de Pós-Graduação, Pontifícia Universidade Católica de São Paulo, São Paulo.

OLIVEIRA, Sabrine Costa. Isometrias por meio de atividades didáticas envolvendo bordado em ponto cruz: investigando a produção de alunos. Trabalho de Conclusão de Curso (Licenciatura em Matemática) - Instituito Federal do Espírito Santo, Vitória - ES, 2014.

PAIS, Luiz Carlos. Uma análise do significado da utilização de recursos didáticos no ensino da geometria. Publicado nos Anais da 23a Reunião da Associação Nacional de Pós Graduação e Pesquisa em Educação - ANPED, Caxambu - MG, setembro 2000. Disponível em: <www.anped.org.br/23/textos/1919t.pdf> Acesso em 20/03/2014.

PAVANELLO, Regina Maria. O abandono do ensino da geometria no Brasil: causas e consequências. In: Zetetiké: Campinas, ano 1, n.1, p. 7-17,1993.

VELOSO, Eduardo; BASTOS, Rita; FIGUEIRINHAS, Sônia. Isometrias e Simetria com materiais manipuláveis. Revista Educação e Matemática. Lisboa, n. 101, p.23-28, 2009. 